\title{
Estado e Comunicação: o caráter público das emissoras estatais. A Rádio Universitária de Goiânia como estudo de caso*
}

\author{
Luiz Signates** \\ Márcia Boaratti***
}

\begin{abstract}
Resumo
Este trabalho tematiza a questão público/privado nas instituições estatais de comunicação. Para isso desconecta teoricamente os conceitos de público e estatal, a fim de estudar as possíveis contradições entre as dimensões do público, do privado, do estatal e do social, na perspectiva de diferentes autores. Como objeto empírico, elege-se a Rádio Universitária, da Universidade Federal de Goiás, analisando particularidades históricas e de funcionamento dessa emissora, a fim de verificar, em grau hipotético, os limites e as possibilidades, bem como os conflitos e contradições vividos pelos sujeitos ali envolvidos. Por fim, discute-se as condições de possibilidade de uma pragmática do público nas emissoras estatais de rádio.

Palavras-chave: público/privado, comunicação e esfera pública, rádio, radiofonia pública.
\end{abstract}

\section{Introdução}

Trata este artigo do relato de uma pesquisa em andamento, cuja problemática teórica central é buscar saber o que significa a noção de

\footnotetext{
*Trabalho apresentado durante o VI Simpósio Regional de Pesquisa em Comunicação - SIPEC-Centro Oeste/INTERCOM, ocorrido em Brasília-DF, de 23 a 24 de maio de 2002.

**Jornalista, professor adjunto da Faculdade de Comunicação e Biblioteconomia da UFG, Coordenador do Curso de Publicidade e Propaganda da Faculdade CamburyGO. Doutor em Ciências da Comunicação pela ECA/USP, Mestre em Comunicações pela FAC/UnB, Especialista em Políticas Públicas pela FCHF/UFG.

***Radialista, Assessora de Projetos da Rádio Universitária/UFG, Professora da Faculdade Cambury-GO. Especialista em Políticas Públicas pela FCHF/UFG.
}

Comun. Inf., v. 4, n. 1/2, p.143-158, jan./dez. 2001 


\section{4}

público, quando aplicada à comunicação social e, em especial, às instituições estatais de comunicação. Essa problematização parte da suspeita de que não basta pertencer ao Estado para que uma instituição seja pública. Nesse sentido, trabalha-se claramente, a partir de diversos autores, com o alargamento social e político da noção de público, para além da conceituação meramente jurídica.

O objeto dessa pesquisa vincula-se à questão das políticas de comunicação e tem sido um dos trabalhos ligados ao Núcleo de Pesquisa em Comunicação e Política da UFG, do qual os autores fazem parte. Por se tratar de uma pesquisa em andamento, os conceitos e análises aqui exarados não devem ser lidos como definitivos, e sim como sinais e resultados parciais de um percurso que ainda exige novos dados para se consolidar.

Assim, este relato partirá de uma análise teórica breve, centrada na evolução da relação público-privado e na emergência do social (Arendt) e das novas esferas públicas (Habermas) ao longo do período histórico que se convencionou chamar de modernidade, até o mundo contemporâneo. Em seguida, propõe-se a análise das condições que caracterizam atualmente a natureza pública de emissoras de rádio estatais no país, tomando como estudo de caso a Rádio Universitária de Goiânia, da Universidade Federal de Goiás. Ao final, procura-se enunciar, em caráter ainda hipotético, algumas conclusões ou indicativos.

\section{O público, o privado, o estatal e o social}

A separação entre público e privado talvez seja a mais importante dicotomia da modernidade. Sua importância é tão considerável que é possível dizer que ela sequer se esgota na consideração etimológica dos dois conceitos que a delimitam. Divisor de águas do mundo capitalista, desde o seu surgimento, a relação público/privado especificase como suprema ordenadora da sociedade ocidental, na institucionalização do Estado e da família, tanto quanto no reconhecimento dos âmbitos da política e da economia.

É Norberto Bobbio quem melhor demonstra a relevância do par público/privado, ao denominá-lo a grande dicotomia, definida como uma distinção capaz de "... dividir um universo em duas esferas, conjuntamente exaustivas (...) e reciprocamente exclusivas (...); ... uma divisão que é ao mesmo tempo total (...) e principal" (Bobbio, 1985, p. 13).

Comun. Inf., v. 4, n. 1/2, p.143-158, jan./dez. 2001 
Esse autor, contudo, não deixa de notar o que por vários pensadores foi caracterizado como decadência do público, isto é, a emergência de um segundo significado para as noções integrantes da dicotomia: a de público como manifesto, publicizado, visível, e a de privado como secreto, íntimo, invisível. Evidentemente, não há como ocultar o conflito entre tais significações, afinal, “... o poder político é o poder público no sentido da grande dicotomia mesmo quando não é público, não age em público, esconde-se do público, não é controlado pelo público" (Bobbio, 1985, p. 28).

Uma mais atenta contextualização da dicotomia público/privado deixa entrever que não se trata simplesmente de um "segundo significado", como pretendeu pontuar o autor italiano. Em seu clássico "A condição humana", Hannah Arendt protesta contra o que ela denominou uma alteração do significado dos dois termos, em relação à sua herança greco-romana, "a ponto de torná-los quase irreconhecíveis. (...) O que hoje chamamos de privado é um círculo de intimidade..." (Arendt, 1958,p. 47-48), fator que teria sido decisivo para o surgimento da sociedade de massas do século 20 . Arendt caracteriza esse fenômeno como sendo o da "emergência do social", definido como o surgimento de um mundo comum referenciado no privado, e não no público, com a conseqüente atrofia deste último, decorrente de sua quase completa despolitização.

A crítica arendtiana da hipertrofia do privado será também assumida por Jürgen Habermas, em seu igualmente clássico "Mudança estrutural da esfera pública" (Habermas, 1961), para quem, à época, o surgimento de uma esfera pública burguesa, definida como reunião de pessoas privadas num público e crítica aos poderes constituídos, deixa de existir com a constituição do Estado burguês - daí a sua "mudança estrutural", descrita como decadência e caracterizada, em termos comunicacionais, pela substituição da "opinião pública" pela mera "opinião publicada".

Essa perspectiva acaba induzindo que a noção de público, definida como visibilidade e discutibilidade das questões políticas e sociais relevantes, perde sua força com o surgimento das sociedades nas quais a comunicação se institucionaliza. No Habermas de "Mudança estrutural", a influência adorniana ainda se faz sentir fortemente, vez que, para sua análise, apesar de as organizações da mídia - a imprensa, mais especificamente - serem "os órgãos por excelência da esfera pública" (Habermas, 1961,p. 15), o "uso publicitário" de conteúdos e

Comun. Inf., v. 4, n. 1/2, p.143-158, jan./der 200' 


\section{6}

formatos significa uma perda considerável, vez que as opiniões não mais brotam da dialogicidade e do conflito de idéias, e sim da sua superexposição e de seu tratamento técnico performático.

Uma visão relativamente simplista do processo comunicativo foi posteriormente abandonada pelo próprio Habermas, com o desenvolvimento de sua teoria da ação comunicativa (Habermas, 1982), na qual o conceito de esfera pública ganha um contorno teoricamente redefinido, como entorno do Estado. Esse autor, em consonância com os intérpretes contemporâneos dos estudos de comunicação, verifica que a multiplicação das tecnologias de comunicação e sua capilarização reticular até os espaços do cotidiano ocasiona, na verdade, uma multiplicação desmedida das esferas públicas, embora não se possa negar o caráter ainda profundamente despolitizado de sua configuração (Habermas, 1985, p. 329-330, e 1990).

De que natureza, contudo, são essas esferas públicas? Até que ponto é possível denominá-las dessa forma? Sem dúvida, esferas públicas "produzidas" pela mídia, no sentido de surgidas de forma quase sempre efêmera, a partir da presença social das instituições de comunicação, devem ser vistas como fenômenos complexos e contraditórios. Complexos, porque dotados de sentidos extremamente diversificados e não raro ambíguos, os quais, se nem sempre se adequam às definições clássicas de "massa" e "multidão", na medida em que configuram manifestação inequívoca de subjetividades populares, igualmente não podem ser tidas como concordes com a denominação clássica de esfera pública. E ambíguos, porquanto esses fenômenos se movimentam de forma conflitiva, dentro mesmo das frágeis e transitórias estruturas de pensamento e prática cultural a que se vinculam, sendo duvidoso até mesmo utilizar tão somente a mídia para explicar-lhes o surgimento e a permanência.

Parece, contudo, suficientemente claro que, com o surgimento midiático contraditório de um público situado como "visível" e, ao mesmo tempo, despolitizado no social, ocorre uma desconexão irreparável com a noção jurídica e consistente de público, como pertencente ao Estado e ao espaço da política. Mesmo essa desconexão ganha contornos de colonização até mesmo do Estado, num momento histórico em que a economia - espaço do privado por excelência alcança uma hipertrofia jamais vista e tende a determinar o sentido do próprio Estado, privatizando-o; mas que, vítima de sua própria importância, ganha simultânea e contraditoriamente a condição de pública,

Comun. Inf., v. 4, n. 1/2, p.143-158, jan./dez. 2001 
já que se torna o objeto principal das políticas públicas e, na medida em que superlativiza a circulação financeira nas jogatinas das bolsas de valores, converte-se em refém das referências simbólicas que todos os dias visitam as mídias e as redes disponíveis de comunicação.

Se, portanto, o público não é o estatal e o estatal nem sempre é utilizado de forma pública, o que pensar das emissoras de comunicação pertencentes ao Estado? Eis a questão que se coloca de forma problemática neste encaminhamento teórico e que nos convoca à pesquisa. Trata-se, a nosso ver, de uma questão que não pode ser respondida de forma simplesmente teórica ou ensaística. O seu tratamento demanda pesquisa empírica, já que, especialmente na América Latina, o público e o privado não possuem fronteiras muito delimitadas, sendo o Estado rotineiramente privatizado, as instituições de comunicação organizadas em familiocracias de origem patriarcal e o mundo privado cotidianizado pelos ritos televisivos. Para estudar esta questão, utilizaremos, portanto, a metodologia do estudo de caso.

\section{Rádio Universitária de Goiânia: um caso típico de emissora estatal}

É cabível, antes de mais nada, fazermos uma justificação metodológica. São vários e diversificados, os critérios que resultaram na escolha da Rádio Universitária de Goiânia como caso para estudo da relação público/privado na comunicação estatal.

O critério que reponta como o principal é a própria especificidade dessa emissora. Mesmo sendo pertencente ao governo federal, pelo fato de estar sob a jurisdição de uma universidade pública, a Rádio Universitária acaba sendo uma emissora bastante independente, demonstrando um grau relativamente alto de autonomia programática. A vinculação à UFG acaba protegendo-a contra influências que geralmente o Estado exerce sobre suas empresas de radiodifusão, o que garante condições importantes de isenção jornalística e independência quanto à definição e à implementação de sua política de programação.

Essa condição de trabalho dos servidores e cooperadores da Rádio Universitária de Goiânia cria um interessante campo metodológico para a análise sociológica de caso, pois configura a possibilidade do reconhecimento - ou não - da condição pública na atuação prática da emissora ou, melhor dizendo, no âmbito das relações concretas estabelecidas entre os diferentes sujeitos que produzem sentido para

Comun. Inf., v. 4, n. 1/2, p.143-158, jan./dez. 2001 


\section{8}

seu funcionamento e sua programação. Para isso, pode-se levar em conta quase completamente a sua dinâmica interna, sem deixar de, com isso, efetuar uma verificação singular de seu relacionamento com o público e os grupos com os quais se relaciona ${ }^{1}$. A aplicação dessa metodologia, contudo, está apenas proposta neste texto, vez que se trata de uma pesquisa em andamento. O que introduzimos neste momento é uma caracterização prévia do campo empírico, a partir dos dados colhidos na administração da emissora.

\subsection{Caracterização do campo de pesquisa}

A Rádio Universitária de Goiânia foi criada em 1962, pela resolução $n^{\circ} 14 / 62$ da Reitoria da UFG. Sua concessão foi dada pelo decreto $\mathrm{n}^{\circ} 56.876$, de 16 de setembro de 1965 . Dessa data até o ano de 1972, a emissora teve seu funcionamento apenas em caráter experimental, com potência de $1 \mathrm{Kw}$, na freqüência de $1400 \mathrm{Khz}$. Somente a partir de 1972, a Rádio Universitária veio a funcionar efetivamente, inclusive como laboratório de jornalismo da UFG e, posteriormente, de Comunicação Social. Em 1996, a Rádio sofreu mudanças de potência, que passou a ser de $20 \mathrm{Kw}^{2}$, e de freqüência, alterada para $870 \mathrm{Khz}$.

A emissora conta hoje com suas instalações divididas em dois locais. Na sede, na Alameda das Rosas, Setor Oeste, em Goiânia, estão concentradas todas as atividades da rádio, tanto as administrativas quanto as relacionadas à programação. No outro espaço, situado no Campus II da UFG, estão instalados os transmissores e a antena. A sede da Universitária possui, além das salas destinadas às tarefas administrativas e de manutenção, três estúdios (sendo dois para gravação), um auditório com 125 lugares, sala de estágio, redação e duas discotecas, uma erudita e outra popular, que abarcam aproximadamente quatro mil títulos em CDs dos mais diversos gêneros musicais.

A Rádio Universitária conta com 26 funcionários em seu quadro fixo. Desses profissionais, dois terços têm formação superior e/ou pósgraduação, e quase a totalidade dos demais possui segundo grau completo. Os profissionais que trabalham diretamente com a programação da emissora incluem-se no primeiro grupo, com formação de terceiro grau. Além desse quadro de funcionários, a Universitária dispõe, além de pessoal terceirizado em áreas de apoio e técnica, de um professor da Faculdade de Comunicação e Biblioteconomia da UFG, responsá-

Comun. Inf., v. 4, n. 1/2, p.143-158, jan./dez. 2001 
vel pela orientação de 30 estudantes. Há ainda um grupo de colaboradores, que, ligados a ONGs e movimentos sociais ou cedidos por outras instituições, desenvolvem produções na emissora.

Desde o seu surgimento até hoje, a emissora não passou por nenhuma transformação significativa. Em 1996, ocorreram transformações que acabaram restritas a questões técnicas. Na ocasião, a frequiência foi modificada de 1400 para 870 , ampliou-se a potência de 1 para $20 \mathrm{KW}$, e ainda houve ampliações e reformas nos estúdios, embora a orientação programática tivesse se mantido inalterada.

Naquele mesmo ano, foi realizado o I Seminário Interno da Rádio Universitária. Foi um momento importante, por ter sido a primeira vez que a emissora parou para uma auto-reflexão. Os seus resultados, entretanto, acabaram reforçando o modelo de rádio educativa e cultural distanciada da sociedade. O que melhor ilustra essa postura conservadora foi a divisão do seminário em dois momentos. O primeiro foi aberto aos funcionários da rádio, bem como a qualquer pessoa que se interessasse. Nesse momento, a dinâmica foi apenas de palestras e debates. A segunda parte do seminário, restrita apenas a funcionários da emissora e professores da Faculdade de Comunicação de UFG, foi quando se discutiu e se deliberou sobre a emissora em geral, definindo finalidade e funções, bem como definindo linhas de programação, formas de locução e prioridade na área de jornalismo.

\subsection{Seminário interno: um debate para poucas mudanças}

Como já foi dito, o ISeminário Interno da Rádio Universitária ocorreu em 1996, após as mudanças no setor técnico da emissora. Esse evento tem relevância, sobretudo, pelo fato de ter gerado um momento de discussão no interior da emissora, além de ter gerado um documento no qual pode se encontrar claramente a proposta de política de comunicação ali praticada. Contudo, o debate não provocou qualquer ruptura ou modificação significativa na linha de trabalho e de programação da Universitária. As resoluções contidas no documento intitulado "Diretrizes Básicas da Rádio Universitária", editado após o Seminário, foram muito mais reafirmações do que já vinha acontecendo na emissora.

As discussões durante o Seminário giraram em torno da natureza e das características do meio rádio, abordando, inclusive, o

Comun. Inf., v. 4, n. 1/2, p.143-158, jan./dez. 2001 


\section{0}

questionamento a respeito da segmentação da programação, da influência da audiência na definição de sua política de programação, da qualidade musical e de quais gêneros e estilos poderiam integrar a programação musical da emissora. A segmentação não foi admitida, ficando a Universitária com uma programação classificada como "pluralista" (Diretrizes Básicas, 1997, p. 7). Quanto à questão da audiência, ficou claro que ela não teria peso considerável para a definição da programação, sendo, inclusive, ressaltado que, se se fosse considerar a audiência, a qualidade ficaria comprometida.

As finalidades da emissora foram reafirmadas como educativa e cultural, permanecendo a compromissada com a prestação de serviços para a construção e defesa da cidadania, com o incentivo à educação e à divulgação de valores da cultura goiana e brasileira. A participação da sociedade em geral, bem como de instituições públicas e privadas, foi defendida como forma de abertura às demandas dos vários segmentos da sociedade, buscando, assim, implementar o que foi chamado de "programação pluralista".

No Seminário, determinou-se que a emissora deve Ter "natureza efetivamente pública", tendo quatro funções básicas: social, educativa, cultural e acadêmica. Essas funções foram estabelecidas segundo uma idéia instrumental de comunicação, sempre pensando a emissora como um canal a ser utilizado para um determinado fim. A função social coloca a emissora à disposição da população, como um canal de expressão na busca da melhoria das condições de vida por meio de programas interativos. A função educativa é difinida principalmente a partir da defesa do direito à educação como dever do Estado, tentando estreitar as relações entre a Universidade e as redes públicas de ensino. Uma das estratégias para atender a essa função é a produção e divulgação de campanhas educativas à saúde, ao meio ambiente e à cidadania, além da integração ao Sistema Nacional de Radiodifusão Educativa - SINRED. A função cultural volta-se para a preservação de uma identidade de cultura local, resgatando, sobretudo, a cultura popular no Estado de Goiás. E a função acadêmica se caracteriza principalmente pela prática laboratorial dos alunos da Faculdade de Comunicação e Biblioteconomia, da Escola de Música e da Escola de Engenharia, todAs da UFG, ressaltando a importância da defesa da universidade pública, da divulgação científica da UFG, bem como da abertura para atividades de extensão.

Comun. Inf., v. 4, n. 1/2, p.143-158, jan./dez. 2001 
Ficou também registrada no documento final do Seminário, a orientação da programação básica da emissora. Para atender as finalidades e as funções citadas acima, foram definidas quatro áreas de produção: musical, educativa/cultural/lazer/entretenimento, jornalística e campanhas educativas. A programação musical tem como base a música popular brasileira e a música instrumental nacional. Outros gêneros, como a música erudita e a sertaneja de raiz, podem ser incluídos na programação, desde que façam parte de programas especiais. A programação ligada à área educativa/cultural/lazer/ entretenimento deve trabalhar a educação formal e informal, podendo utilizar programas produzidos pela própria emissora ou por outras instituições, buscando envolver a Universidade nos trabalhos realizados pela emissora. Nessa área, inclui-se a divulgação da cultura local e nacional. O jornalismo da Universitária deve dar ênfase à divulgação científica da UFG, bem como levar à discussão grandes temas atuais, sendo que o formato privilegiado foi o de boletins curtos, distribuídos por toda a programação. As campanhas educativas são definidas a partir das demandas sociais da população em geral, com o objetivo central de melhorar a qualidade de vida do cidadão, o que acaba caindo em um discurso vazio de sentido, podendo Ter diversos significados, visto que trata a população como um grupo homogêneo, no qual as demandas não são diferenciadas ou mesmo conflitivas.

\subsection{A Universitária hoje: algumas hipóteses para a análise}

Uma análise consistente da natureza pública da Rádio Universitária não pode, claramente, se manter nas condições discursivas formais ou meramente legais de seu funcionamento. Se observarmos a caracterização da emissora, a partir de seus documentos, verificamos que sua vinculação com o Estado e com a Universidade aparecem como determinantes de seu sentido programático. A relação público-privado na comunicação social é, contudo, mais complexa e demanda, para se evitar os equívocos formalistas de análise, uma observação detida das condições e relações concretas efetivamente estabelecidas. Eis a que esta pesquisa se propõe.

Em termos conjeturais, porém, é possível efetuar uma análise prévia das condições da Rádio Universitária, levando em consideração, sobretudo, a experiência profissional vivida ali pelos autores deste tra-

Comun. Inf., v. 4, n. 1/2, p.143-158, jan./dez. 2001 


\section{2}

balho. Apesar disso, tais observações não podem deixar de ser percebidas a partir de um valor hipotético, sob pena de as considerações de caráter metodológico, feitas anteriormente, perderem seu valor epistemológico, o que de forma alguma seria adequado.

Uma análise prévia da organização da emissora deixa entrever o funcionamento de uma típica repartição pública: a Diretoria Geral e, hierarquicamente ligada a ela, três departamentos, uma Assessoria de Projetos e uma Coordenação de Estágio/laboratório, cada qual responsável por uma área de atuação e de influência, com as suas devidas chefias ou coordenações. A atuação dessas divisões internas não configuram um quadro sinérgico, uma unidade de trabalho na Rádio. Ao contrário, são comuns os conflitos, nos quais interesses e demandas internas parecem se sobrepor àqueles que fariam sentido, conforme os documentos definidores das políticas a serem cumpridas.

A Diretoria, a Assessoria de Projetos, bem como os departamentos, possuem somente profissionais do quadro fixo da emissora. Os estudantes apenas trabalham, sob a coordenação do professor designado pela Faculdade de Comunicação. Aqui já podemos notar uma das mais importantes divisões internas que acontecem na Rádio: a que separa a Rádio Universitária dos profissionais e a Rádio Universitária dos estudantes. Essa divisão, que tem características políticas e não apenas de papéis, parece ser uma das principais geratrizes de uma clara indefinição da linha de programação. Existem horários reservados para o laboratório/estágio, nos quais a programação segue uma orientação independente do restante da programação da rádio. É uma programação, na maioria das vezes, experimental, mas que tem uma coisa em comum com a programação dos profissionais: a pretensão de oferecer uma qualidade única, que só eles podem proporcionar, para um público desconhecido, sem um perfil delineado.

Além dos profissionais e estudantes, há ainda a figura dos "colaboradores", profissionais voluntários ou cedidos por outras instituições estatais, geralmente ligados a movimentos sociais e artístico-culturais, responsáveis por alguns programas da emissora. São de certa forma vinculados ao Departamento Artístico e de Programação, mas também desenvolvem o seu trabalho de maneira independente, desconectada com as demais áreas de atuação programática.

A divisão interna também ocorre entre os próprios profissionais da emissora. Temos o Departamento Artístico e de Programação, o Departamento de Jornalismo e o Departamento Técnico. Os dois primei-

Comun. Inf., v. 4, n. 1/2, p.143-158, jan./dez. 2001 
ros são os responsáveis pela maior parte da programação musical e jornalística que é veiculada. Não há, entretanto, uma integração entre eles. Cada qual parece trabalhar como se fizesse parte de uma emissora diferente, tal como acontece entre os alunos e os profissionais. Essa divisão, que deveria ser apenas um modo de organizar a administração, acaba determinando a existência de fronteiras, demarcadoras de áreas de domínio dentro da emissora. De um ponto de vista programático, é plausível dizer que existem várias rádios, cada qual com sua linguagem, seu estilo e, o que talvez seja o mais relevante, portadora da capacidade de definição de critérios próprios para o desenvolvimento de seu trabalho. Com isso, o produto final tende a assumir um modelo de programação cujo resultado certamente pode se definir pela metáfora da "colcha de retalhos"3.

Como não se tem uma definição clara de público, e, ainda, como a audiência não é um parâmetro definidor da programação, uma das hipóteses levantadas é a de que o trabalho realizado na emissora toma por base a intuição do que pode vir a ser o público-alvo ${ }^{4}$ ou o que talvez seja o mais certo: cada pessoa ou grupo de pessoas, que toma parte nos trabalhos relacionados com a programação da rádio, desenvolve o seu trabalho tendo como base o seu gosto pessoal, usando como justificativa legitimadora ou ideológica o argumento relacionado à qualidade e ao seu caráter educativo/cultural. Aliás, a experimentação também é usada como critério de trabalho pelo laboratório dos cursos de comunicação da UFG, embora aí sua justificação se baseie em argumentos de tipo pedagógico e, neste caso específico, dentro de uma fundamentação que parece mais pertinente, o que, contudo, não altera a impressão de desconexão e fragmentação do que poderia ser uma política pública específica de programação radiofônica.

A verdade aparente - e que, aqui, adquire um alto valor hipotético, pelo seu potencial de definição teórica e histórica - é que, desde o seu início, na década de 60 , a Universitária mantém vários pontos em comum com o modelo de radiofonia da década de vinte, época do surgimento do Rádio no Brasil. Essa afirmação apóia-se na constatação de que, apesar de todas transformações ocorridas no meio rádio, a Universitária parece manter a sua programação musical e informativa voltada para camadas altas e médias da sociedade ${ }^{5}$. Pode-se também dizer que sua definição como uma emissora educativa e cultural acaba direcionando-a à elaboração de uma política de programação pragmaticamente conservadora, no sentido de não estar aberta a inova-

Comun. Inf., v. 4, n. 1/2, p.143-158, jan./dez. 2001 


\section{4}

ções, de tender a veicular apenas aquilo que se mostra como padrão legitimado de qualidade.

Outro ponto que leva a comparar a Rádio Universitária com o modelo de Rádio de Roquete Pinto é a opção por não segmentar a programação. A alegaçãoé que uma emissora pública não pode privilegiar uma parcela da sociedade em detrimento de outras e, por isso, não se deve direcionar a programação para um único público ou, mais especificamente, para apenas parcelas da sociedade.

Esse argumento tem algumas fragilidades que importa destacar. Primeiro, porque a segmentação acaba ocorrendo por conta das próprias escolhas programáticas, independentemente de ser ou não uma política da emissora. Segundo, porque o desejo de não se fragmentar o público desencadeia uma fragmentação da própria programação e, o que parece mais relevante, dentro de uma lógica em que é justamente a sociedade a mais desconsiderada. $\mathrm{O}$ que se vê na programação da Universitária é uma diferenciação de conteúdos e formatos que reflete única ou prioritariamente a divisão de grupos internos da emissora.

A ausência de consideração para com o público se faz aparente também no tom formal e distanciado da locução. Nesse sentido, é possível aventar que a emissora busca se distanciar do público, mantendo-se na posição discursiva de quem detém o conhecimento em oposição aos ouvintes, ou firmando-os discursivamente como inaptos para decidir o que é bom ou ruim, o que devem ou não ouvir.

Todos esses sinais, reunidos, parecem dar alta plausibilidade para a construção de uma hipótese geral: as políticas de programação da Rádio Universitária não visam estabelecer uma relação de igualdade entre a emissora e a sociedade e, portanto, nem mesmo de serviço público, embora, contraditoriamente, essa situação possa esporadicamente acontecer numa ou noutra concretização de atividade comunicativa na pragmática da programação ${ }^{6}$.

\section{Algumas conclusões teóricas}

E é justamente nessa discussão que se mostra pertinente a questão-problema deste estudo: no âmbito do funcionamento das instituições estatais de comunicação social, a natureza jurídica de seu estatuto institucional é condição insuficiente para determinar a sua natureza pública. Ao render-se ao funcionamento burocrático-administrativo que

Comun. Inf., v. 4, n. 1/2, p.143-158, jan./dez. 2001 
caracteriza historicamente os governos, as emissoras estatais vinculam-se à condição sistêmica do Estado, tendendo, por um lado, à endogenia funcional descrita pelas teorias de sistema e arriscando-se, por outro, a estabelecer uma relação, senão de conflito, no mínimo de indiferença, com o entorno social determinado pela abrangência de seu sinal. Em outras palavras, tais emissoras tendem a privilegiar interesses internos, relacionados aos grupos que disputam as pequenas fatias de poder simbólico em jogo na produção dos sentidos programáticos e burocráticos, e, com isso, tendem a se tornar contrários ou indiferentes aos públicos conectados.

Parece também interessante analisar isso em comparação com as emissoras privadas e comerciais. Estas instituições de comunicação vivem a permanente tensão entre, por um lado, servir aos públicos conectados, ainda que objetivando exclusivamente uma conectividade praticamente sem conteúdo, formulada no conceito abstrato e quantitativo de "audiência", e, por outro lado, servir aos sujeitos anunciantes, numa troca sistêmica em que essa audiência serve de output em permuta com o input da sustentação e do lucro da emissora. Essa tensão é sempre irresolvida, pois se enraíza na contradição entre os interesses do mundo econômico e os do mundo social, mantendo-se em perpétua renovação, uma vez que o valor econômico é quase imediatamente definido a partir das quantidades de audiência aferidas em pesquisa. Trata-se, nesse caso, justamente da tensão público/privado, traduzida pela contradição entre o valor da "publicidade" (ato e efeito de tornar algo acessível a públicos generalizados) e o do interesse econômico, pela mediação abstrata das estatísticas, ou, na ausência destas, por pressupostos de uso de gêneros e formatos musicais relacionados aos extratos de audiência.

O modo como se institucionalizam sistemicamente as emissoras estatais é, sem dúvida, de ordem inteiramente diferente das emissoras privadas. Isso porque a presença garantidora do Estado, na forma do autofinanciamento orçamentário e da estabilidade das contratações, elimina os riscos, existentes nas emissoras comerciais, decorrentes de um acentuado descolamento das audiências conectadas. Se, por um lado, essas garantias institucionais podem favorecer a consideração de um interesse público de natureza universal e vinculado a ações de mais longo prazo, por outro desencadeiam novas contradições, que aparecem na forma do corporativismo, das lutas de poder ou de aparelha-

Comun. Inf., v. 4, n. 1/2, p.143-158, jan./dez. 2001 


\title{
156
}

mentos político-partidários, em cujas origens estão, não raro, interesses especificamente privados dos sujeitos envolvidos.

Se, enfim, nas emissoras privadas, a contradição aparece na luta privada entre um público convertido em social e um privado traduzido no econômico, no âmbito das emissoras estatais, a contradição parece surgir na luta pública entre um privado determinado por facções internas em conflito e um interesse público considerado abstratamente em desconexão com o mundo social concreto. Em ambos os casos, devido às relações serem determinadas, em perspectiva habermasiana, por sentidos sistêmicos, sempre em conflito com o mundo da vida, o caráter especificamente público - no sentido da democracia deliberativa garantida eticamente por interações de tipo comunicativo e institucionalmente pela constituição de esferas públicas plurais e amplas - aparece altamente comprometido.

Trata-se, pois, de se repensar o conceito de público, quando aplicado à institucionalização e ao funcionamento das organizações de comunicação, sejam estatais ou privadas. No caso específico das emissoras estatais, trata-se de efetuar, em definitivo, a desconexão teóricoconceitual entre público e estatal, admitindo a natureza sistêmica do Estado e das próprias instituições de comunicação, para, em seguida, reconhecer as contradições que emergem do funcionamento pragmático dessas instituições e conferir um novo sentido ao caráter público que se quer delas. Consideramos, por hipótese, que, nessa perspectiva, o conceito de esfera pública parece bastante heurístico para abrir novas possibilidades de análise e atuação.

\begin{abstract}
This work approaches the public/private question in the state institutions of communication. For that, it disconnects theoretically the concepts of public and state, in the perspective of peculiar authors. As empirical object, it elects the RU/UFG, analyzing historical and operational particularities. Finally, it also discusses the conditions of possibility of a pragmatic of the public in the state radios. radio.

Keywords: public/private, comunication and public sphere, radio, public

\section{Notas}

1. Uma análise de natureza metodológica das instituições sistêmicas de comunicação eletrônica (rádio e televisão), visando contemplar as relações
\end{abstract}

Comun. Inf., v. 4, n. 1/2, p.143-158, jan./dez. 2001 
internas e programáticas pela perspectiva dos sujeitos significativos (ou agentes programáticos), é feita em outro artigo (Signates, 1996).

2. Apesar da instalação do novo transmissor, problemas de ordem burocrática e administrativa, que preferimos não analisar neste trabalho, impediram que a emissora funcionasse regularmente na nova potência.

3. Essas considerações, relacionadas aos conteúdos e formatos da programação da emissora, têm ainda, como já foi dito, um caráter apenas hipotético, embora se baseiem em constatações e evidências experienciais dos autores, sendo plausível crer que tenham, por isso, razoável grau de pertinência. De todo modo, sua confirmação (ou não) depende da aplicação, prevista no projeto original, de uma análise crítica do discurso programático, em conexão com os dados sociológicos colhidos durante a pesquisa de campo.

4. A noção de "público-alvo imaginado", seja a advinda dos estudos da nova retórica (Perelman e Olbrechts-Tyteca, 1958, p. 22), seja a originada da análise do discurso (Orlandi, 1988, p. 9) ou, ainda, a trabalhada pelos teóricos do news making (Wolf, 1985, p. 188), parece fundamental para os estudos da comunicação, dentro de uma abordagem intersubjetivista, isto é, aquela que leva em alta conta a presença, ainda que virtual, do assim chamado "receptor", como figura obrigatória nos processos de produção da comunicação.

5. É forçoso admitir que essas considerações se baseiam em pressupostos de gosto musical e informativo aplicados conjeturalmente pelos autores ao perfil da programação da emissora. Tratam-se de considerações plausíveis, uma vez que a própria literatura desse campo de estudos jamais deixou de avaliar o modelo educativo de rádio e televisão por essa perspectiva (ver, por exemplo, Ortriwano, 1985, p. 14; Santos, 1985, p. 59; Caparelli, 1982, p. 79). Tal plausibilidade não dispensa, contudo, pesquisas de audiência que venham a confirmá-las ou não, mas que, devido às características e às próprias possibilidades materiais existentes, jamais foram feitas em relação à Rádio Universitária.

6. A análise orientada pragmaticamente permite, nesse caso, um importante cuidado metodológico, o de evitar, o quanto possível, que a articulação teórica, por mais pertinente e sedutora que pareça ser, venha a obscurecer a natureza sempre complexa e contraditória das práticas que se procura explicar. Nesse caso específico, a hipótese de trabalho busca garantir sentidos gerais, sem abandonar as possibilidades de contradições, na dinâmica das práticas em exercício.

\section{Referências}

ARENDT, Hannah. A condição humana. Rio de Janeiro: Forense Universitária, 1995.

BOBBIO, Norberto. Estado, governo, sociedade: por uma teoria geral da política. Rio de Janeiro: Paz e Terra, 1987.

CAPARELLI, Sérgio. Comunicação de massa sem massa. São Paulo : Cortez, 1982.

SEMINÁRIO DA RÁDIOUNIVERSITÁRIA DA UFG, I., 1997, Goiânia. Diretrizes Básicas. Goiânia: CEGRAF/UFG, 1997.

Comun. Inf., v. 4, n. 1/2, p.143-158, jan./dez. 2001 


\section{8}

HABERMAS, Jürgen. Mudança estrutural da esfera pública: investigações quanto a uma categoria da sociedade burguesa. Rio de Janeiro : Tempo Brasileiro, 1984.

HABERMAS, Jürgen. The theory of the communication action. V. I e II. Boston: Beacon Press, 1984.

HABERMAS, Jürgen. Discurso filosófico da modernidade. Lisboa: Dom Quixote, 1998.

HABERMAS, Jürgen. Further reflections on the public sphere. In: CALHOUN, Craig, (Org.). Habermas and the public sphere. Cambridge/Massachusetts: MIT Press, 1997. p. 421-461

ORLANDI, Eni P. Discurso e leitura. São Paulo: Cortez; Campinas: Ed. da Universidade Estadual de Campinas, 1993.

ORTRIWANO, Gisela. A informação no rádio: os grupos de poder e a determinação dos conteúdos. São Paulo: Summus, 1985.

PERELMAN, Chaïm.; Olbrechts-Tyteca, Lucie. Tratado da argumentação: a nova retórica. São Paulo: Martins Fontes, 1996.

SANTOS, Maria S. T. Rádio no Brasil: o discurso da modernização sem mudança. Cadernos Intercom, v. 4, n. 8, p. 55-60, dez. 1985.

SIGNATES, Luiz. Metodologia da pesquisa sobre programação. LondrinaPR: GT Rádio/Intercom, 1996. Paper.

WOLF, Mauro. Teorias da comunicação. Lisboa: Presença, 1987.

Comun. Inf., v. 4, n. 1/2, p.143-158, jan./dez. 2001 